\title{
Shock Initiation of 2,4-Dinitroimidazole (2,4-DNI)
}

\author{
P. A. Urtiew \\ C. M. Tarver \\ R. L. Simpson
}

This paper was prepared for submittal to the 1995 American Physical Society Topical Conference

Shock Compression of Condensed Matter Seattle, Washington

August 13-18, 1995

July 19, 1995

This is a preprint of a paper intended for publication in a journal or proceedings. Since changes may be made before publication, this preprint is made available with the understanding that it will not be cited or reproduced without the permission of the author. 


\section{DISCLAIMER}

This document was prepared as an account of work sponsored by an agency of the United States Government. Neither the United States Government nor the University of California nor any of their employees, makes any warranty, express or implied, or assumes any legal liability or responsibility for the accuracy, completeness, or usefulness of any information, apparatus, product, or process disclosed, or represents that its use would not infringe privately owned rights. Reference herein to any specific commercial product, process, or service by trade name, trademark, manufacturer, or otherwise, does not necessarily constitute or imply its endorsement, recommendation, or favoring by the United States Government or the University of California. The views and opinions of authors expressed herein do not necessarily state or reflect those of the United States Government or the University of California, and shall not be used for advertising or product endorsement purposes. 


\section{DISCLAIMER}

Portions of this document may be illegible in electronic image products. Images are produced from the best available original document. 


\title{
SHOCK INITIATION OF 2,4-DINITROIMIDAZOLE (2,4-DNI)
}

\author{
P. A. Urtiew, C. M. Tarver and R. L. Simpson \\ Lawrence Livermore National Laboratory, \\ P.O. Box 808, L-282, Livermore, CA 94551
}

\begin{abstract}
The shock sensitivity of the pressed solid explosive 2,4-dinitroimidazole (2,4-DNI) was determined using the embedded manganin pressure gauge technique. At an initial shock pressure of $2 \mathrm{GPa}$, several microseconds were required before any exothermic reaction was observed. At $4 \mathrm{GPa}, 2,4-$ DNI reacted more rapidly but did not transition to detonation at the $12 \mathrm{~mm}$ deep gauge position. At $6 \mathrm{GPa}$, detonation occurred in less than $6 \mathrm{~mm}$ of shock propagation. Thus, 2,4-DNI is more shock sensitive than TATB-based explosives but is considerably less shock sensitive than HMX-based explosives. An Ignition and Growth reactive flow model for 2,4-DNI based on these gauge records showed that 2,4-DNI exhibits shock initiation characteristics similar to TATB but reacts faster. The chemical structure of 2,4-DNI suggests that it may exhibit thermal decomposition reactions similar to nitroguanine and explosives with similar ring structures, such as ANTA and NTO.
\end{abstract}

\section{INTRODUCTION}

The five membered ring explosive 2,4dinitroimidazole (2,4-DNI) was first synthesized by Lancini et al. (1) by nitrating 2-nitroimidazole. It was later obtained by the thermal rearrangement of 1,4-DNI (2). Currently 2,4-DNI is being made from 4-nitroimidazole, which is commercially available (3). This allows 2,4-DNI to be produced in large quantities in a cost effective manner. The goal of the synthesis project is to produce a relatively inexpensive explosive that has a higher energy density than TATB and TNT, yet is still insensitive. The small scale safety properties, thermal explosion behavior, and detonation velocity versus charge density of 2,4-DNI were reported by Jayasuriya et al. (3). In this paper, the shock sensitivity of 2,4-DNI was measured at three shock pressures using embedded manganin gauge techniques (4) and calculated using the Ignition and Growth reactive flow model (5) for shock initiation and detonation in the DYNA2D hydrodynamic code (6).

\section{EXPERIMENTAL}

The experimental geometry is shown in Fig. 1 . A $12.7 \mathrm{~mm}$ thick, $60 \mathrm{~mm}$ diameter Lexan flyer plate impacted a target consisting of a $6 \mathrm{~mm}$ thick, $90 \mathrm{~mm}$ diameter Teflon buffer plate and a $25 \mathrm{~mm}$ thick, 50.8 mm diameter 2,4-DNI charge. The 2,4-DNI charge was held in place by a $3 \mathrm{~mm}$ thick Lexan ring. Six $0.3 \mathrm{~mm}$ thick Teflon-insulated manganin gauges were placed in pairs along the center line of the 2,4DNI charge at distances of 0,6 , and $12 \mathrm{~mm}$. Three experiments were fired in the $100 \mathrm{~mm}$ powder gun with Lexan flyer velocities of $0.979 \mathrm{~mm} / \mu \mathrm{s}, 1.518$ $\mathrm{mm} / \mu \mathrm{s}$ and $2.273 \mathrm{~mm} / \mu \mathrm{s}$, producing initial shock pressures of approximately $2 \mathrm{GPa}, 4 \mathrm{GPa}$ and $6 \mathrm{GPa}$, respectively. The measured changes in resistance of the manganin gauge elements were converted to



FIGURE 1. Experimental geometry for the shock initiation experiments on 2,4-DNI

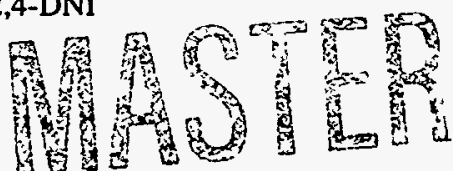


pressure histories and compared to Ignition and Growth reactive flow calculations.

\section{REACTIVE FLOW MODELING}

The Ignition and Growth reactive flow model (5) has been incorporated into several hydrodynamic codes and used to solve many explosive and propellant safety and performance problems (7). The model uses two Jones-Wilkins-Lee (JWL) equations of state, one for the unreacted explosive and another one for the reaction products, in the temperature dependent form:

$$
p=A e^{-R_{1} V}+B e^{-R_{2} V}+\omega C_{v} T
$$

where $\mathrm{p}$ is pressure in Megabars, $\mathrm{V}$ is relative volume, $T$ is temperature, $\omega$ is the Gruneisen coefficient, $C_{v}$ is the average heat capacity, and $A, B$, $R_{1}$ and $R_{2}$ are constants. The equations of state are fitted to the available shock Hugoniot data. The reaction rate law is:

$$
\begin{aligned}
& d F / d t=I(1-F)^{b}\left(\rho / \rho_{o}-1-a\right)^{x}+G_{1}(1-F)^{c F d} p^{y} \\
& 0<\mathrm{F}<\text { Figmax } \quad 0<\mathrm{F}<\mathrm{FG} 1 \text { max } \\
& +\mathrm{G}_{2}(1-\mathrm{F})^{\mathrm{e}} \mathrm{Fg}^{\mathrm{z}} \\
& \mathrm{F}_{\mathrm{G} 2 \mathrm{~min}}<\mathrm{F}<1
\end{aligned}
$$

where $F$ is the fraction reacted, $t$ is time, $\rho$ is the current density, $\rho_{o}$ is the initial density, $p$ is pressure in Megabars, and $I, G_{1}, G_{2}, a, b, c, d, e, g, x, y$, and $z$ are constants. As explained in previous papers (4), this three term reaction rate law models the three

TABLE 1. Equation of state and reaction rate parameters

$$
\text { 1. Ignition and Growth Model Parameters for 2,4-DNI }
$$$$
\text { Unreacted JWL Product JWL }
$$$$
\rho_{0}=1.67 \mathrm{~g} / \mathrm{cm}^{3}
$$$$
A=2700 \text { Mbar }
$$$$
\mathrm{B}=-0.0519165 \mathrm{Mbar}
$$$$
\mathrm{R}_{1}=13.0
$$$$
\mathrm{R}_{2}=1.30
$$$$
\omega=0.9
$$$$
\mathrm{C}_{\mathrm{V}}=3.0 \mathrm{e}-5 \mathrm{Mbar} / \mathrm{K}
$$$$
\mathrm{T}_{\mathrm{O}}=298^{\circ} \mathrm{K}
$$

Shear Modulus $=0.035 \mathrm{Mbar}$

Yield Strength $=0.002$ Mbar

$$
\begin{aligned}
& A=6.113 \mathrm{Mbar} \\
& B=0.1065 \mathrm{Mbar} \\
& R_{1}=4.40 \\
& R_{2}=1.20 \\
& \omega=0.32 \\
& C_{V}=1.0 \mathrm{e}-5 \mathrm{Mbar} / \mathrm{K} \\
& E_{0}=0.089 \mathrm{Mbar}
\end{aligned}
$$

stages of reaction generally observed during shock initiation of heterogeneous solid explosives. The first term ignites some of the solid explosive as it is compressed by a shock or compression wave creating heated areas (hot spots) as the voids in the material collapse. Generally the amount of explosive ignited by a strong shock wave is approximately equal to the original void volume. The second term in Eq. (2) represents the relatively slow growth of reaction from the hot spots into the surrounding solid in a deflagration-type process. The third term in Eq. (2) describes the rapid transition to detonation observed when the growing hot spots begin to coalesce and transfer large amount of heat to the remaining unreacted particles, causing them to react very quickly and to create a high pressure pulse which overtakes the leading shock front and thus causes detonation. The equation of state parameters for 2,4DNI, Lexan, and Teflon and the Ignition and Growth rate law parameters used in the reactive flow calculations are listed in Table 1. The measured

\begin{tabular}{|c|c|c|c|c|c|c|c|}
\hline \multirow[b]{2}{*}{ Inert } & \multicolumn{7}{|c|}{$\begin{array}{c}\mathrm{p}=\rho_{0} c^{2} \mu\left[1+\left(1-\gamma_{0} / 2\right) \mu-\mathrm{a} / 2 \mu^{2}\right] /\left[1-\left(S_{1}-1\right) \mu-S_{2} \mu^{2} /(\mu+1)-S_{3} \mu^{3} /(\mu+1)^{2}\right]^{2}+\left(\gamma_{o}+\mathrm{a} \mu\right) E \\
\text { where } \mu=\rho / \rho_{0}-1 \text { and } \mathrm{E} \text { is thermal energy }\end{array}$} \\
\hline & $\rho_{o}\left(\mathrm{~g} / \mathrm{cm}^{3}\right)$ & $\mathrm{c}(\mathrm{mm} / \mathrm{ms})$ & $s_{1}$ & $\mathrm{~s}_{2}$ & $s_{3}$ & $\gamma_{0}$ & $\mathbf{a}$ \\
\hline 6061-T6 Al & 2.703 & 5.24 & 1.4 & 0. & 0.0 & 1.97 & 0.48 \\
\hline Lexan & 1.193 & 1.933 & 2.04 & 0. & 0.0 & 0.61 & 0.0 \\
\hline Teflon & 2.1 & 1.68 & 1.123 & 3.98 & -5.8 & 0.59 & 0.0 \\
\hline
\end{tabular}
pressure histories and those predicted by the Ignition and Growth model are compared in the next section.

\section{COMPARISON OF RESULTS}

Figure 2 compares the experimental pressure histories (solid lines) with those predicted by the Ignition and Growth model (dashed lines) for the lowest pressure 2,4-DNI experiment with a Lexan flyer velocity of $0.979 \mathrm{~mm} / \mu \mathrm{s}$, which imparts a 2 GPa shock pressure into the 2,4-DNI charge. The 0 $\mathrm{mm}$ gauges measured very little growth of reaction for the first $6 \mu$ s after impact, and then the pressure

2. Gruneisen Parameters for Inert Materials

\section{Reaction Rate Parameters}

$\begin{array}{ll}I=2.0 e+8 & G_{2}=25 \\ a=0.0 & e=0.667 \\ b=0.667 & g=0.667 \\ x=15.0 & z=2.0 \\ G_{1}=9.5 & F_{i g m a x}=0.3 \\ y=1.0 & F_{G 1 \max }=1.0 \\ c=0.667 & F_{G 2 \min }=0.3 \\ d=0.333 & \end{array}$




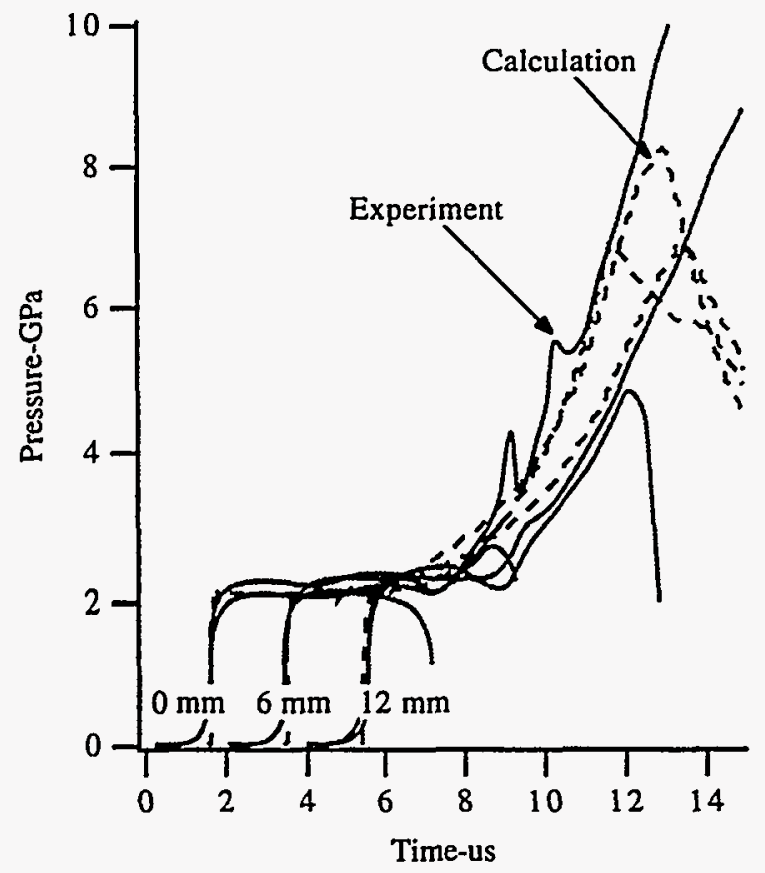

FIGURE 2. Pressure histories for 2,4-DNI impacted at $0.979 \mathrm{~mm} / \mu \mathrm{s}$ by a Lexan flyer plate

rose slowly to $3 \mathrm{GPa}$ over the next $\mu$ s before the gauges failed. The $6 \mathrm{~mm}$ deep gauges recorded no pressure increase for the first $3 \mu \mathrm{s}$, followed by a continuous growth to over $10 \mathrm{GPa}$ in the next $5 \mu \mathrm{s}$. The $12 \mathrm{~mm}$ deep gauges recorded similar pressure histories. The Ignition and Growth model pressure histories exhibit similar continuous energy releases up to about 8 to $9 \mathrm{GPa}$, corresponding to approximately $50 \%$ reaction. At this shock pressure, TATB-based explosives do not react (8), and HMXbased explosives exhibit a faster growth of reaction behind the shock front than does 2,4-DNI (9).

.Figure 3 shows the experimental and calculated pressure histories for 2,4-DNI impacted by Lexan at $1.518 \mathrm{~mm} / \mu \mathrm{s}$, creating a $4 \mathrm{GPa}$ shock. At this shock amplitude, TATB-based explosives do not react, while HMX-based explosives transition to detonation at run distances of less than $10 \mathrm{~mm}(10)$. The gauge records in Fig. 3 clearly show that 2,4DNI is not close to detonating at the $12 \mathrm{~mm}$ gauge position. Although the $0 \mathrm{~mm}$ gauge records are not very good, the other 4 gauges clearly show some shock front amplitude increase at the 6 and $12 \mathrm{~mm}$ depths, followed by a pressure growth to $11 \mathrm{GPa}$ over the next $3 \mu \mathrm{s}$ at the $12 \mathrm{~mm}$ gauges. The Ignition and Growth model calculates these increases accurately by allowing about 3\% reaction during shock compression (ignition) and a subsequent reaction rate with a $\mathrm{p}^{1}$ dependence.



FIGURE 3. Pressure histories in 2,4-DNI impacted at $1.518 \mathrm{~mm} / \mu \mathrm{s}$ by a Lexan flyer

The experimental and calculated results for the highest Lexan flyer velocity experiment, 2.273 $\mathrm{mm} / \mu \mathrm{s}$, producing a $6 \mathrm{GPa}$ shock are shown in Fig. 4. The $0 \mathrm{~mm}$ gauges record a rapid growth reaction to $12 \mathrm{GPa}$ over $2 \mu \mathrm{s}$. The 6 and $12 \mathrm{~mm}$ gauges record high pressures characteristic of a detonation wave. The Ignition and Growth calculations agree closely with the gauge records and predict that detonation occurs just before the reactive shock reaches the $6 \mathrm{~mm}$ gauge. At a shock pressure of 6 $\mathrm{GPa}, \mathrm{HMX}$-based explosives detonate in about 4 $\mathrm{mm}$, while TATB-based explosives do not decompose to any significant degree. Therefore, 2,4DNI is much more reactive than TATB at $6 \mathrm{GPa}$, but but not as reactive as most explosive molecules.

\section{SUMMARY}

The shock sensitivity of 2,4-DNI has been determined using embedded manganin pressure gauges and the Ignition and Growth reactive flow model. Its shock initiation characteristics have been shown to be similar to TATB-based explosives in that a shock of sufficient strength to ignite a few percent of the charge then exhibits some amplitude growth as it propagates through the charge, followed by a growth of reaction that can be modeled with a linear pressure dependence. The transition to detonation then occurs in the usual fashion when the growing pulse pulse overtakes the leading shock front. Since it reacts 


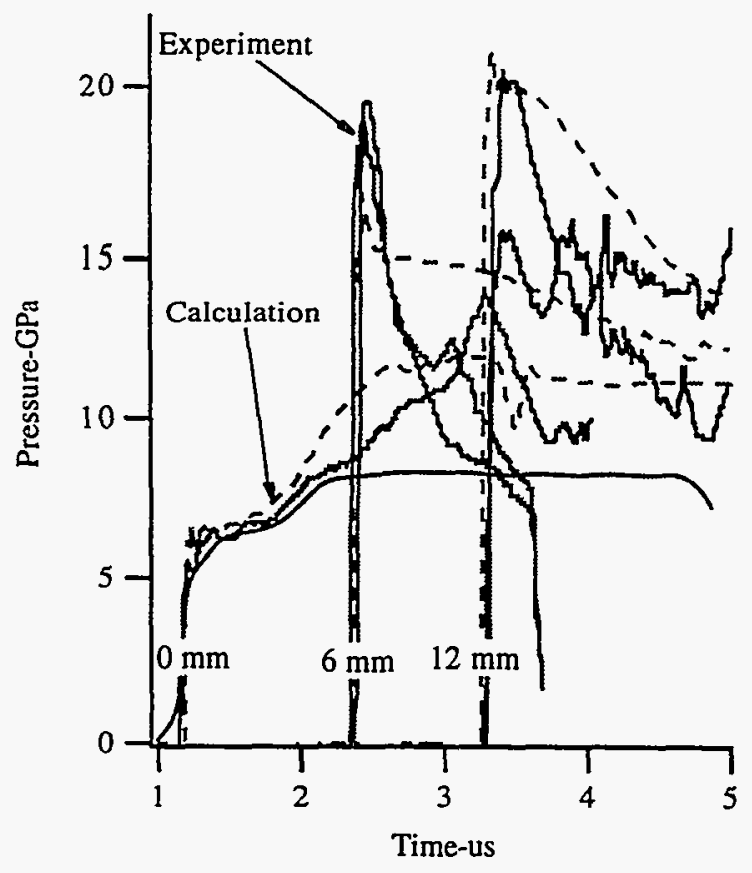

FIGURE 4. Pressure histories for 2,4-DNI impacted at $2.273 \mathrm{~mm} / \mu \mathrm{s}$ by a Lexan flyer

relatively slowly at 2 and $4 \mathrm{GPa}$ shock pressures, 2,4-DNI is definitely less shock sensitive than HMX. Since it reacts slowly at 2 and $4 \mathrm{GPa}$ and detonates within $6 \mathrm{~mm}$ at $6 \mathrm{GPa}, 2,4-\mathrm{DNI}$ is more shock sensitive than TATB. However, since most hazard scenarios involve shock pressures well below $6 \mathrm{GPa}$, 2,4-DNI may be shock insensitive enough for many applications.

Williams et al. (11) have studied the thermal decomposition of several explosives with ring structures similar to that of 2,4-DNI, such as 3-nitro1,2,4-triazol-5-one (NTO) and 3-amino-5-nitro-1,2,4triazole (ANTA), and found that these compounds partially decompose forming a polymer-like residue called melon. Thus 2,4-DNI should decompose in a similar manner. Since at least one of these compounds, nitroguanidine, exhibits Group 2 explosive behavior (12), 2,4-DNI may also fall into this category.

\section{ACKNOWLEDGEMENTS}

The authors would like to thank Dr. K. Jayasuriya and Dr. R. Damauarapu of the Army Research and Development Center for furnishing the 2,4-DNI used in this study. The authors also would like to thank Frank Garcia for firing the $100 \mathrm{~mm}$ gun shots and Leona Meegan for assembling the embedded gauge targets.
This work was performed under the auspices of the U.S. Dept. of Energy by Lawrence Livermore National Laboratory under contract No. W-7405ENG-48.

\section{REFERENCES}

1. Lancini, G. C., Maggi, N., and Sensi, P., Farmaco (pavia), Ed. Sci., 18, 390-395 (1963)

2. Shamin, G. P., Fassakhov, R. Kh., and Orlov, P. P., USSR Patient 458553 (1975).

3. Jayasuriya, K., Damauarapu, R., Simpson, R. L., Coon, C. L., and Colburn, M. D., "2,4-Dinitroimidazole: A Practical Insensitive High Explosive," Lawrence Livermore National Laboratory Report UCRL-JC-ID-1 13364, March 1993.

4. Urtiew, P. A., Erickson, L. M., Hayes, B., and Parker, N. L., Combustion, Explosion and Shock Waves 22, 597-614 (1986).

5. Tarver, C. M.. Hallquist, J. O., and Erickson, L. M.. in Eighth Symposium (International) on Detonation, Naval Surface Weapons Center NSWC 86-194. Albuquerque. NM, 1985, pp. $951-961$.

6. Whirley, R. G., Engelmann, B. E., and Hallquist, J. O. "DYNA2D User Manual," Lawrence Livermore National Laboratory Report UCRL-MA-110630, April 1992.

7. Tarver, C. M., Urtiew, P. A., Chidester, S. K., and Green, L. G., Propellants, Explosives, Pyrotechnics 18, $117-127$ (1993).

8. Tarver, C. M., Propellants, Explosives, Pyrotechnics 15, 132 142 (1990).

9. Lee, E. L. and Tarver, C. M., Phys. Fluids 23, 2362-2372 (1980).

10. Dobratz, B. M. and Crawford, P. C., "LLNL Explosives Handbook," Lawrence Livermore National Laboratory Repor UCRL-52997, January 1985.

11. Williams, G. K., Palopolli S. F., and Brill, T. B., Combustion and Flame 98, 197-204 (1994).

12. Price, D., Clairmont, A. R., and Erkman, J. O., Combustion and Flame 17, 323-336 (1971). 